indicate that this is but one facet of a general failure by Indians to appreciate the merits of their country's scientists, as shown by the relatively poor salaries paid to those working in academic circles and also by the tendency to employ foreign scientific advisers in preference to local talent. In conclusion, Dr. Hora discussed the stepping-up of the biological sciences in India, and in this connexion the Institute has decided to recommend that departments for the special study of certain subjects should be established as follows: a marino biological station at Bombay; is central freshwater biological station at Mettur, Madras State; animal genetics at a cancer research centre in Bombay, a eytogenetics research wing at: the University of Calcutta and a cytochemistry research wing at the University of Mysore; and plant genetics at the Indian Agricultural Research Institute, Delhi.

\section{Electron Microscopy of Plant Cilia}

Further observations on the structure of plant cilia, by a combination of visual and electron microscopy, are given by I. Manton, B. Clarke, A. D. Greenwood and E. A. Flint in the current issue of the Journal of Experimental Botany (3, No. 8, 204 ; 1952). The cilia of zoospores of Saprolegnia ferax, Chlorosaccus ulvaceus, Allomyces arbuscula and Olpidium brassicce are illustrated by some excellent photographs at magnifications ranging from $\times 2,000$ (visual light under an oil immersion objective) to $\times 20,000$ (electron micrograph). The flagella of these micro-organisms (three fungi and a yellow-green alga) showed eleven component strands, these usually being clearly differentiated into a central pair and nine others. These strands are observable in specimens which are undergoing fibrillar disintegration. Similar strand numbers have also been observed in ferns and in green and brown algæ. Stained and unstained specimens of Saprolegnia and Chlorosaccus have been closely compared in the electron microscope and the nature of the artefacts produced by staining investigated. Visual and electron micrograph records of one and the same stained cell have also been compared. Observation of the very distinctive but closely comparable flagellar character in brown algæ, yellowgreen algæ and certain fungal and flagellate groups has led the authors to the conclusion that these groups are phyletically more nearly related to each other than they are to other groups, for example, green algæ (see also p. 280 of this issue of Nature).

\section{General Principles of University Research}

IN Research for Industry (4, No. 5 ; July 1952), the news bulletin of Stanford Research Institute, Dean Ernest R. Hilgard, of the Graduate Division of Stanford University, writing on "Fundamental and Applied Research in relation to the University", lays down three criteria for the choice of possible research projects by a university, including research grants or contracts offered by industry or government. First, the project should be in line with the professor's special interest and training; second, it should preferably be of a kind to make good use of the students and to provide them with a rounded training in research; third, it should normally lead to scholarly publication. These criteria do not exclude applied research, since it can meet these standards provided the inquiries are conducted in the true scientific spirit. Examining the kinds of research which normally should be less favoured by a university, Dean Hilgard lays down four further criteria.
First, projects serving the immediate aims of industry or government but lying outside the scholarly interests of the staff and not in the direction of intended development; second, those requiring a pace of development best served by non-teaching scientists and full-time technicians ; third, specialized projects requiring a staff so large as to disturb the equilibrium of the university; and fourth, research which requires excessive travel away from the university.

\section{Latin-American Course in São Paulo on Radio- isotope Methodology}

A CoUrse on radioisotope mothodology, the first of its kind ever to be held in Latin America, has been organized by the Faculty of Medicine of the University of São Paulo, Brazil, under the direction of Prof. A. Wormall, who has been temporarily seconded from the Department of Biochemistry and Chemistry, St. Bartholomew's Hospital Medical College, London, assisted by Dr. Tede Eston, Dr. Veronica Rapp de Eston, Prof. P. B. Smith and Miss Constancia Pagano, of São Paulo. The course, which started on January 14 and is a full-time one, lasting for six weeks, consists of two whole days of practical work each week together with theoretical lectures on the experiments to be made ; in addition, four theoretical lectures are being given weekly and seminars held in connexion with the laboratory work. Those taking the course are graduates in science or medicine, and thirty men and women are at prosent participating, nineteen being from Brazil and eleven being holders of Unesco fellowships from other Latin-American countries; the limitation in numbers is due to the difficulties of accommodating the practical work, but there is no restriction on the numbers who may attend the lectures, and, in fact, four others are doing so. Most of the participants hold responsible positions in universitics, research institutions or hospitals, and it is hoped that the course will enable them to make profitable use of radioactive isotopes for research and for clinical medicine. Further details can be obtained from the Laboratório de Isótopos, Faculdade de Medicina, Caixa Postal 2921, São Paulo, or the Divisão de Difusão Cultural, Reitoria da Universidade de São Paulo, rua Helvetia 49 a 55, São Paulo.

\section{Physical Society's Annual Exhibition}

THE thirty-seventh annual exhibition of scientific instruments and apparatus arranged by the Physical Society will be held during April 13-17 in the Imperial College of Science and Technology, Imperial Institute Road, London, S.W.7. A return has been made to the practice of former years of plasing the whole of the exhibition in the main buildings of the College (except for one heavy exhibit housed in the Mathematics Department of the Huxley Building, Exhibition Road, for which tickets of entry will not be required. Three discourses, each lasting approximately forty-five minutes, will be given at 6.45 p.m. in the Large Chemistry Lecture Theatre as follows: April 14, Dr. E. C. Bullard (National Physical Laboratory), "Seismic Study of Ocean Basins"; April 15, Dr. L. A. Jordan (Paint Research Station), "Particles, Pellicles ; Pigments, Paints and Physics"; April 16, Prof. W. V. Mayneord (Department of Physics, Royal Cancer Hospital), "Scintillation Counting and its Medical Applications". A handbook giving details of the exhibits will be published early in March and will be available at the exhibition or ordered from the Physical Society (price 6s., or 